\title{
Modified Salter osteotomy for the treatment of developmental dysplasia of the hip
}

\author{
DESCRIPTION OF A NEW TECHNIQUE THAT ELIMINATED THE USE \\ OF PINS FOR INTERNAL FIXATION
}
A. Eren,
M. Pekmezci,
G. Demirkiran,
M. Cakar,
M. Guven,
M. Yazici

From Hacettepe University, Ankara, Turkey

\begin{abstract}
A. Eren, MD, Associate Professor

M. Cakar, MD, Orthopaedic Surgeon

M. Guven, MD, Consultant Department of Orthopaedics Ministry of Health, Goztepe Training Hospital, Dr Erkin Cad, Istanbul 34730, Turkey.

M. Pekmezci, MD, Clinical Fellow

G. Demirkiran, MD, Clinical Fellow

M. Yazici, MD, Professor of Orthopaedics

Department of Orthopaedics Hacettepe University Faculty of Medicine, Sihhiye, Ankara
\end{abstract} 06100, Turkey.

Correspondence should be sent to Professor M. Yazici; e-mail: yazioglu@hacettepe.ed.tr

(c)2007 British Editorial Society of Bone and Joint Surgery doi:10.1302/0301-620X.89B10. $18704 \$ 2.00$

$J$ Bone Joint Surg $[\mathrm{Br}]$ 2007;89-B:1375-8.

Received 28 September 2006; Accepted after revision 14 May 2007

The Salter innominate osteotomy has been used successfully for many years in the treatment of developmental dysplasia of the hip. One of its main drawbacks is the need for internal fixation with pins and their subsequent removal. We describe a modification of this osteotomy that does not require pin fixation and secondary removal. We retrospectively reviewed 114 hips in 94 patients who had been operated on by a single surgeon. An oblique rather than the original horizontal osteotomy was used without internal fixation. There were 80 female and 14 male patients. The mean age at operation was 25 months (18 to 84) and the mean follow-up was 30 months (12 to 88). Most patients required additional open reduction and capsuloplasty. The mean pre-operative acetabular index was $37.9^{\circ}\left(24^{\circ}\right.$ to $\left.54^{\circ}\right)$, which decreased to $19.9^{\circ}\left(7^{\circ}\right.$ to $\left.29^{\circ}\right)$ in the immediate post-operative period, and improved to $14.6^{\circ}\left(5^{\circ}\right.$ to $\left.25^{\circ}\right)$ at the final follow-up (student's $t$-test, $\left.p<0.0001\right)$.

We believe that by changing the direction of the osteotomy line, it is possible to avoid pin fixation. The radiological outcomes are comparable to those of the original technique, but longer follow-up will be necessary.

In 1961, Salter ${ }^{1}$ introduced the innominate osteotomy for the treatment of developmental acetabular dysplasia. Since that time, excellent results have been achieved with this procedure, not only in the treatment of developmental dysplasia of the hip (DDH), but also in Perthes' disease, and teratological dislocations. ${ }^{2-4}$ However, there remain some associated problems. One is the need for internal fixation to control the graft and the distal fragment. Complications of fixation include pin breakage, joint penetration, and pin migration with or without secondary graft displacement. ${ }^{5-8}$ In some children, the iliac crest may be very thin and the pins used for internal fixation may damage the graft itself. A second operation to remove the pins is necessary. In this retrospective study, we present a modification of the Salter osteotomy which is relatively stable and does not require internal fixation.

\section{Patients and Methods}

The study group was composed of patients with a diagnosis of DDH who were operated on between 1997 and 2004. The operations were performed by a single surgeon (AE) and the radiological evaluation by two independent orthopaedic surgeons (MP and GD), who were not members of the department. Patients who had a complete set of radiographs with a minimum follow-up of 12 months were included in the study.

Surgical technique. The patients are operated on in the supine position with a sandbag under the ipsilateral hip. An anterolateral approach is used. The straight head of the rectus femoris is elevated from the anterior inferior iliac spine and the reflected head transected. The iliopsoas tendon is divided at the pelvic brim. When open reduction is necessary, the capsule is opened by an incision parallel to the edge of the acetabulum and an inverted U flap raised from the femoral side. ${ }^{9}$ The ligamentum teres and the transverse acetabular ligament are excised. The iliac wing is exposed subperiosteally and two Hohmann retractors placed in the sciatic notch. The osteotomy starts approximately $15 \mathrm{~mm}$ above the acetabulum between the anterior superior and the anterior inferior iliac spines, and runs obliquely into the sciatic notch (Fig. 1a). It is performed with an osteotome under direct vision and the osteotomy line is parallel to the acetabular surface on the anteroposterior (AP) view. The superior articular margin of the acetabulum is followed to determine the angle of the osteotomy. Secondary to the oblique direction of the osteotomy, the distal part of the ilium lies parallel to the floor when 


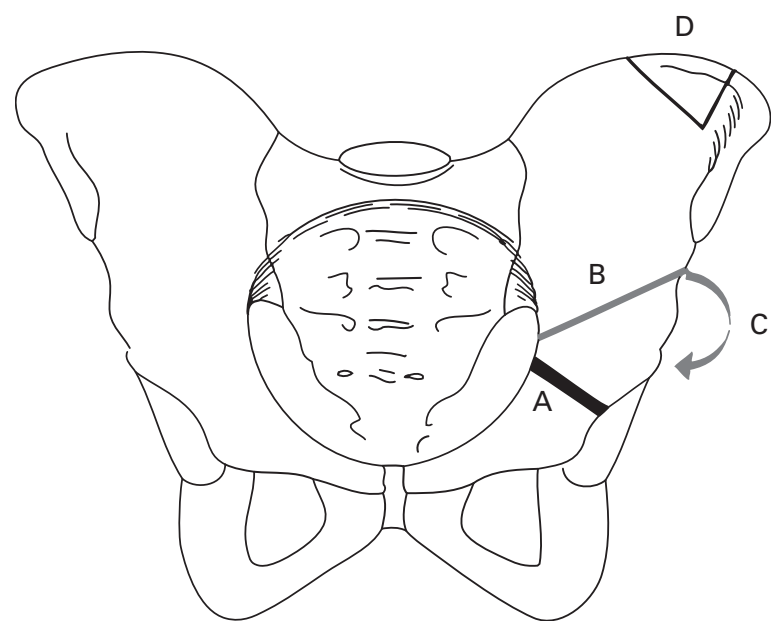

Fig. 1a

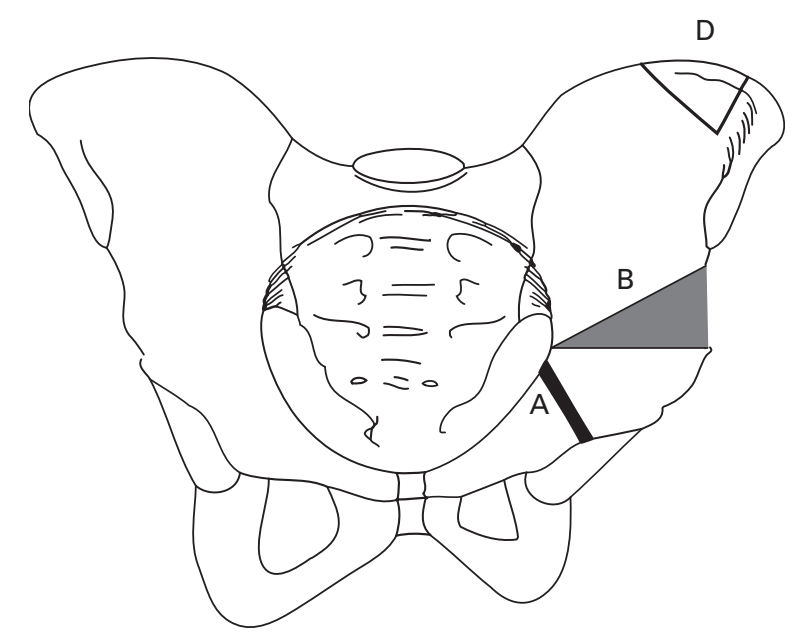

Fig. 1b

Drawings showing a) the osteotomy performed $15 \mathrm{~mm}$ above the acetabulum and the line of the osteotomy directed obliquely into the sciatic notch and b) after placement of the graft, the distal end of the osteotomy becomes parallel to the ground. A, triradiate cartilage; B, osteotomy line; C, acetabular redirection; $\mathrm{D}$, bone graft.

the osteotomy line is opened by using towel clips on both sides (Fig. 1b). A triangular graft is taken from the ipsilateral iliac wing, with sides approximately $15 \mathrm{~mm} \times 25 \mathrm{~mm}$ long, and is placed into the osteotomy perpendicular to the weight-bearing axis. The stability is tested in the mediolateral direction and by a push-pull test, pushing the ipsilateral hip upwards. Pins are inserted if the surgeon is not satisfied with the stability of the graft; otherwise no internal fixation is used. In patients who have required open reduction, the hip is relocated; the $U$ flap is inverted and sutured to the anteromedial acetabulum, and excess capsule excised. Patients are put into a hip spica for six to eight weeks and the wound not inspected unless clinically indicated. An abduction orthosis is then used for three months.

Radiological evaluation. The pre-operative radiographs were evaluated and the hips classified using the Tönnis classification. ${ }^{10}$ The acetabular index was measured on the AP pelvic radiographs pre-operatively, immediately postoperatively, and at final follow-up. The immediate postoperative radiograph was reviewed for graft tilting or dislocation. The final follow-up radiographs were evaluated for subluxation or redislocation. We did not evaluate the radiographs for avascular necrosis for two reasons. First, this was a report of a modified technique and we focused on the corrective capacity of the osteotomy. Secondly, follow-up was relatively short, and to evaluate patients for AVN reliably they should be followed until skeletal maturity.

Statistical analysis. This was performed using SPSS 11.0 software (SPSS Inc., Chicago, Illinois). Following demonstration of the normal distribution of the data, the acetabular indices were compared using Student's $t$-test.

\section{Results}

Between 1997 and 2004, 134 hips were operated upon in 110 patients. Of these patients, 16 were excluded secondary to inadequate follow-up (minimum follow-up 12 months). A total of 94 patients (80 females and 14 males; 114 hips) therefore, qualified for the study. We excluded four patients (four hips) because the graft was unstable and pin fixation was necessary; 20 patients had bilateral involvement. The mean age at the time of operation was 25 months (18 to 84$)$. The mean follow-up was 30 months (12 to 88$)$. Three hips $(2.7 \%)$ were Tonnis grade I, $50(45.5 \%)$ were grade II, $32(29.1 \%)$ were grade III, and $25(22.7 \%)$ were grade IV. Most patients had no treatment prior to the procedure. Three were treated with a Pavlik harness, four had prior closed reduction, and one had undergone an open reduction. None of the patients had pre-operative traction. In addition to modified Salter osteotomy, open reduction and capsuloplasty was required in 100 hips (91\%). Eight patients $(8.9 \%)$ required additional procedures to obtain a stable hip. Five patients had a combined procedure of open reduction, pelvic osteotomy and femoral shortening with derotation, one had a varus and one a valgus femoral osteotomy and one a derotation osteotomy.

The mean pre-operative acetabular index was $37.9^{\circ}$ $\left(24^{\circ}\right.$ to $\left.54^{\circ}\right)$. Immediately post-operatively, it was $19.9^{\circ}\left(7^{\circ}\right.$ to $29^{\circ}$ ) (Student's $t$-test, $\mathrm{p}<0.0001$ ) and at final follow-up, it had further improved to $14.6^{\circ}\left(5^{\circ}\right.$ to $25^{\circ}$ ) (Student's $t$-test, $\mathrm{p}<0.0001$ ) (Fig. 2).

Complications. Five patients $(5.5 \%)$ had a superficial infection which healed uneventfully. None had a deep infection or haematoma. In the immediate post-operative period, two patients $(2.2 \%)$ had tilting of the graft which did not compromise the reconstruction, as the acetabular indices at 


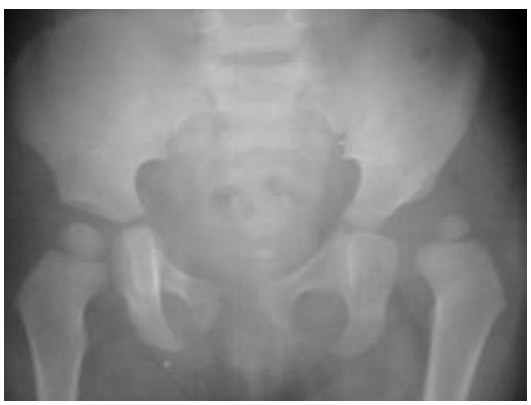

Fig. 2a

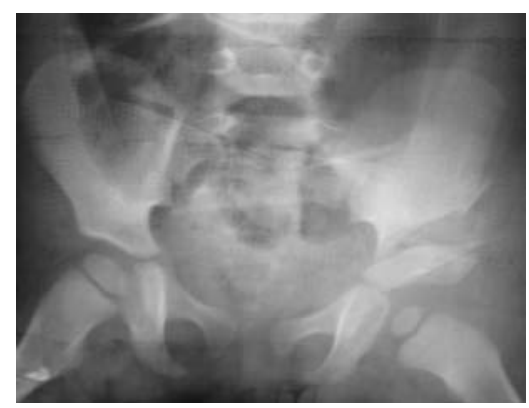

Fig. $2 b$

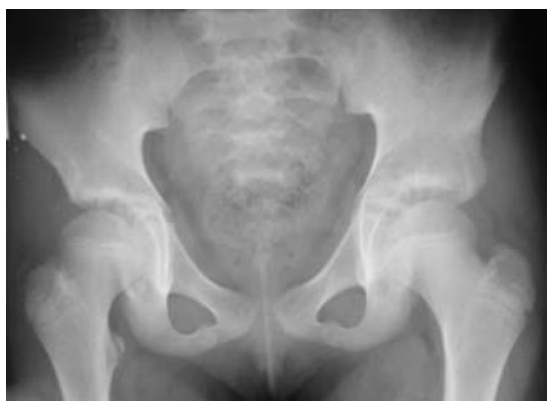

Fig. 2c

Anteroposterior radiograph showing a) pre-operative acetabular index of $44^{\circ}$ in a two-year-old girl. The acetabular index reduced b) to $15^{\circ}$ in the immediate post-operative period and c) to $14^{\circ}$ at five-year follow-up.

final follow-up were $13^{\circ}$ and $18^{\circ}$, respectively. There was no redislocation, but five patients $(5.5 \%)$ developed subluxation. Four of these had an acetabular index ranging between $12^{\circ}$ and $18^{\circ}$ at final follow-up. One patient had an acetabular index of $26^{\circ}$ at final follow-up.

\section{Discussion}

Several pelvic osteotomies have been developed to improve acetabular cover. Several studies have verified the safety and efficacy of the Salter osteotomy. ${ }^{11-16}$ However, it is not free of complications such as graft or pin displacement, $7,11,13,16$ redislocation of the hip, $, 6,11,13$ haematoma and superficial infection, ${ }^{5,7,12,14,15,17}$ deep infection, ${ }^{7,14,15}$ persistent stiffness of the hip joint, ${ }^{7}$ femoral fracture, and AVN of the femoral head. ${ }^{6,7,11,12,17}$

Because this osteotomy is inherently unstable, some form of internal fixation is inevitable. Salter ${ }^{1}$ described the use of Kirschner (K)-wires for fixation, and this remains currently the most common form of fixation. Some authors have observed pin migration into the pelvis and suggested the use of threaded pins to avoid this. ${ }^{6}$ Such implants are usually removed later, which increases the morbidity and the cost of the procedure. Kremli ${ }^{17}$ suggested the use of biodegradable pins, which produced comparable results and eliminated the need for a second operation. Kalamchi ${ }^{18}$ described a modification where the distal fragment fits into a notch in the ilium, which increases the stability of the osteotomy. Marafioti and Westin ${ }^{8}$ described a modification in which a greenstick fracture is produced in the remaining portion of the ischium. The inherent stability provided by this fracture enabled them to eliminate pins for internal fixation. In this study, we describe a modification in which the osteotomy is complete and no internal fixation is needed. This has the advantage that it eliminates complications from the pins and a second procedure to remove them.

In the classic Salter osteotomy, the distal fragment is inclined downwards, which makes the graft prone to displacement. The technique which we describe follows the same philosophy, but uses an oblique osteotomy. Following the redirection of the osteotomy, the distal iliac fragment becomes horizontal, which produces a more stable situation for the bone wedge. We suggest this is the main factor that increases stability. However, we recognise that this is speculative, and further biomechanical studies should be undertaken to test the stability of the modified osteotomy. The change in the direction of the osteotomy does not compromise the redirection potential. Radiological evaluation demonstrated that the modified pinless Salter osteotomy produced similar results to the original osteotomy. The acetabular index was restored to within normal limits in the immediate post-operative period and continued to improve thereafter. Lin et $\mathrm{al}^{15}$ reported a mean of $13^{\circ}$ of correction, whereas Bohm and Brzuske ${ }^{13}$ reported a mean of $11.9^{\circ}$ of correction with a Salter osteotomy. Ito et $\mathrm{al}^{14}$ reported a mean $16.4^{\circ}$ improvement in the acetabular index. The mean correction of $18^{\circ}$ in this series was comparable to those reported in the literature. Elimination of the need for internal fixation should reduce the length of the procedure to some extent, but we did not have a control group, and are unable to comment on reduction in operating time.

Complications related to pin placement may reach $7.4 \%$. Some are related directly to the pins, and others are indirect, such as loss of correction secondary to pin misplacement. As we did not use pins in this series, there were no complications directly related to them. In the literature, the rate of graft displacement ranges between $0 \%$ and $17 \% .{ }^{5,7,13,16,17}$ In this series, the rate of graft displacement was $2 \%$. This low rate of graft dislocation may be the result of the care taken to verify the stability of the graft with this technique. There were five superficial infections (4\%), which was comparable to previous reports. $5,7,12,14,16,17$ There were no deep infections and no further dislocations although there were five $(4 \%)$ subluxations. However, four of these had an acetabular index with normal limits at final follow-up. These results are similar to those of previous studies $7,11-13,16$ These patients were among the early patients in the series when the operating surgeon (AE) had a very low threshold for fixation. If there was any concern 
about stability during intra-operative testing, we used pin fixation. These patients might have healed uneventfully without pin fixation, but we did not wish to take the risk of graft displacement. We believe that testing for intraoperative stability is an important part of this modification, and the surgeon should not hesitate to add pin fixation if there is any question of instability.

There are limitations to this study. We did not report the rate of AVN, as the patients were not followed up to skeletal maturity. This is a report of a modified technique and we believe the current follow-up is acceptable. All operations were performed by a single surgeon, which increases the homogeneity of the patient group. We did not evaluate the patients for limb lengthening or the hips for anterior cover.

In summary, we believe that pinless Salter osteotomy is a safe and effective method to treat DDH. It eliminates the need for a second procedure and complication rates are comparable to those of the original technique. Further studies should be undertaken to report the reproducibility of the technique by different surgeons as well as the long-term clinical and radiological outcome.

No benefits in any form have been received or will be received from a commercial party related directly or indirectly to the subject of this article.

\section{References}

1. Salter RB. Innominate osteotomy in the treatment of congenital dislocation and subluxation of the hip. J Bone Joint Surg [Br] 1961;43-B:518-39.

2. Salter RB, Dubos JP. The first fifteen year's personal experience with innominate osteotomy in the treatment of congenital dislocation and subluxation of the hip. Clin Orthop 1974;98:72-103

3. Kitakoji T, Hattori T, Kitoh H, Katoh M, Ishigoro N. Which is a better method for Perthes' disease: femoral varus or Salter osteotomy? Clin Orthop 2005;430:163-70.
4. LeBel ME, Gallien R. The surgical treatment of teratologic dislocation of the hip. J Pediatr Orthop B 2005;14:331-6.

5. Barrett WP, Staheli LT, Chew DE. The effectiveness of the Salter innominate osteotomy in the treatment of congenital dislocation of the hip. J Bone Joint Surg [Am] 1986;68-A:79-87.

6. Fournet-Fayard J, Kohler R, Michel CR. Results of Salter's innominate osteotomy in residual hip dysplasia in children: a propos of 60 cases. Rev Chir Orthop Reparatrice Appar Mot 1988;74:243-51 (in French).

7. Gur E, Sarlak 0. The complications of Salter innominate osteotomy in the treatment of congenital dislocation of the hip. Acta Orthop Belg 1990;56:257-61.

8. Marafioti RL, Westin GW. Factors influencing the results of acetabuloplasty in children. J Bone Joint Surg [Am] 1980;62-A:765-9.

9. Eren A, Altinas F, Atay EF, Omeroglu H. A new capsuloplasty technique in open reduction of developmental dislocation of the hip. J Pediatr Orthop B 2004;13:13941.

10. Tonnis D. Normal values of the hip joint for evaluation of $x$-rays in children and adults. Clin Orthop 1976;119:39-76.

11. Huang SC, Wang JH. A comparative study of nonoperative versus operative treatment of developmental dysplasia of the hip in patients of walking age. J Pediatr Orthop 1997;17:181-8.

12. Haidar RK, Jones RS, Vergroesen DA, Evans GA. Simultaneous open reduction and Salter innominate osteotomy for developmental dysplasia of the hip. J Bone Joint Surg [Br] 1996;78B:471-6.

13. Bohm P, Brzuske A. Salter innominate osteotomy for the treatment of developmental dysplasia of the hip in children: results of seventy-three consecutive osteotomies after twenty-six to thirty-five years of follow-up. J Bone Joint Surg [Am] 2002;84-A:178-86.

14. Ito H, Ooura H, Kobayashi M, Matsuno T. Middle-term results of Salter innominate osteotomy. Clin Orthop 2001;387:156-64.

15. Lin CJ, Lin YT, Lai KA. Intraoperative instability for developmental dysplasia of the hip in children 12 to 18 months of age as a guide to Salter osteotomy. J Pediatr Orthop 2000;20:575-8.

16. Macnicol MF, Bertol P. The Salter innominate osteotomy: should it be combined with concurrent open reduction? J Pediatr Orthop B 2005;14:415-21.

17. Kremli M. Bioabsorbable rods in Salter's osteotomy. J Pediatr Orthop B 2002;11:104-9.

18. Kalamchi A. Modified Salter osteotomy. J Bone Joint Surg [Am]1982;64-A:183-7. 